Article

\title{
Effects of Long-Term Supplementation with Brown Seaweeds and Polyphenols in Rabbit on Meat Quality Parameters
}

\author{
Raffaella Rossi ${ }^{1, *}$, Francesco Vizzarri ${ }^{2}$,, Sabrina Ratti ${ }^{1}$, Marisa Palazzo ${ }^{3}$, \\ Donato Casamassima ${ }^{3}$ and Carlo Corino ${ }^{1}$ (D) \\ 1 Dipartimento di Medicina Veterinaria, Università Degli Studi di Milano, Via dell’Università 6, \\ 26900 Lodi, Italy; sabrinaratti@hotmail.com (S.R.); carlo.corino@unimi.it (C.C.) \\ 2 Department of Agricultural and Environmental Science, Università di Bari Aldo Moro, \\ Via G. Amendola 165/A, 70126 Bari, Italy; francesco.vizzarri@uniba.it \\ 3 Department of Agricultural, Environmental and Food Sciences, Università Degli Studi del Molise, \\ Via F. De Sanctis 1, 86100 Campobasso, Italy; m.palazzo@unimol.it (M.P.); casamassima.d@unimol.it (D.C.) \\ * Correspondence: raffaella.rossi@unimi.it
}

Received: 13 November 2020; Accepted: 17 December 2020; Published: 20 December 2020

check for updates

Simple Summary: Safe and natural feed supplement are required to enhance animal health and welfare, answering to the agri-food system and consumers' needs. The research for sustainable feed additives for enhancing rabbit health and meat quality parameters are needed. Plants received considerable consideration as safe feed supplements in animal nutrition. Recent studies indicated that seaweed can be considered a sustainable dietary supplement that improve animals' health and meat quality parameters. Moreover, plant polyphenols have been studied as antioxidants and cholesterol-lowering agents in meat. No data on the effects of long term dietary supplementation of a mixture composed of brown seaweed and plant polyphenols has been available. For this reason, we decided to test the effects of dietary natural supplements in rabbits, based on performance and meat quality parameters.

\begin{abstract}
The objective of the present study was to evaluate the effects of dam and offspring dietary supplementation with a natural feed additive on the growth performance and meat quality parameters of growing rabbits. The growing rabbits are selected from lactating does receiving a control diet (C) or diets supplemented with $0.3 \%$ (SP1) and $0.6 \%$ (SP2) of feed additive containing brown seaweeds (Laminaria spp.) and plant extracts. In the postweaning phase, the growing rabbits remained in the treatment group defined by their does and the trial lasted 42 days. The average daily feed intake and feed conversion ratio were improved in the rabbit fed $0.6 \%$ of the natural feed additive. The cholesterol content tended to be lower in Longissimus lumborum (LL) muscle and decrease in Semimembranosus (SM) muscle (in SP2 $-41.36 \%$ than controls). The $\alpha$ tocopherol and retinol content were enhanced in both muscles of rabbit fed the natural mixture (SP1 and SP2 groups). An improvement of sensory attributes of texture was observed in both muscles from rabbit fed natural mixture. In conclusion, long term supplementation of both lactating does and offspring with the high dosage of brown seaweed and plant polyphenols improves growth performance and enhances meat nutritional and sensory parameters.
\end{abstract}

Keywords: brown seaweed; meat quality parameters; plant polyphenols; rabbit 


\section{Introduction}

The EU is the second highest world producer of meat rabbits. The majority $(83 \%)$ of production is in Spain (48.5 million rabbits slaughtered), followed by France (29 million rabbits slaughtered) and Italy (24.5 million rabbits slaughtered). Rabbit meat represents a traditional dietary practice in the Mediterranean area and a new source of consumption in China and Mexico [1-3].

Even if the global rabbit meat consumption per capita is low if compared with other meat $(0.19 \mathrm{~kg} /$ per capita/year), in EU countries the consumption is about $0.51 \mathrm{~kg} /$ per capita/year (Spain $1.09 \mathrm{~kg}$; Italy $0.91 \mathrm{~kg}$; France $0.75 \mathrm{~kg}$ ) [3].

In the last decades, the genetic selection has turned towards improvement of the offspring number, growth rate and muscle mass. This causes some problems related to global farm efficiency $[4,5]$. In rabbit farming several diseases occur; digestive disorders are the main problem, affecting antibiotics consumption [6].

Considering that the EU has been committed for years towards a rational use of antibiotics in livestock, nutrition can be one potential efficient strategy for improving rabbit health and meat quality. Additional research that explores the effects of dietary sustainable additives and alternative feed ingredients in rabbit are required.

Moreover, in recent years, the demand for healthy foods that respect the environment and animal welfare has increased [7]. For products of animal origin, the idea of healthy and safe is linked not only to the product nutritional composition but also to the diet, additives, and antibiotics that the animals have taken. In fact, a strong consumers' preference for natural food, free from synthetic additives and antibiotics was observed [8].

Several studies reported that dietary integration with plant extracts containing polyphenols in rabbit improves health, increases nutrient digestibility and growth performances and enhances meat quality parameters $[9,10]$. Plant extracts offer a considerable range of activities such as antioxidant, anti-inflammatory, antiviral and antimicrobial effects, positively influencing feed digestibility and microbial ecology [6].

Other studies showed that dietary brown seaweeds in livestock had a positive effect on health, growth performance, and meat quality due to their nutraceuticals properties and content of sulfated polysaccharides, phlorotannins, diterpenes, omega-3 polyunsaturated fatty acids, minerals and vitamins [11,12]. Moreover, brown seaweeds represent a renewable and sustainable feed ingredient for their high productivity if compared to other conventional ingredients.

Our previous study reported the effects of a mixture of brown seaweeds and plant polyphenols on the performance of lactating does [13]. Moreover, we also investigated the effect of the same natural supplementation in growing rabbits [14]. In literature, no previous study reported the effects of long term supplementation in rabbit with brown seaweed and plant polyphenols from lactating does to rabbit slaughter. Therefore, we wanted to evaluate if dietary treatments during the entire rabbit rearing period may positively affect the growing rabbit's productive performance and meat quality parameters.

\section{Materials and Methods}

\subsection{Animals and Dietary Treatments}

Rabbits were handled following the guidelines of EU Directive 2010/63/EU and national guidelines for the care and use of animals [15]. All experimental procedures involving animals were approved by the National Agricultural and Food Centre ethical committee (No. NPPC 18-10-2016).

The dietary supplementation began in the lactation phase in which does $(n=60)$ were divided into three experimental groups, homogeneous for body weight $(4.83 \pm 0.19 \mathrm{~kg})$ and parity order (second), receiving a control diet (C) or diets supplemented with $0.3 \%$ (SP1) and $0.6 \%$ (SP2) of feed additive containing prebiotic polysaccharides from brown seaweeds (Laminaria spp.) and plant extracts containing phenolic acid, hydroxycinnamic acids, tannins, and flavonoids. In the postweaning period, all rabbits remained in the treatment group defined by their does. The trial lasted 42 days. 
The dosages of the supplement were chosen based on an in vitro study on the minimal inhibitory concentration (MIC) against Clostridium spp., Staphylococcus spp., and Escherichia coli spp. [16].

No anticoccidials, antibiotics or other medications were included in the diet. The feed additive was included in the mashed diets, then the diets were pelleted.

At weaning (35 days), 144 New Zealand White rabbits, balanced for body weight and sex were housed at the National Agricultural and Food Centre, Nitra (Slovak Republic).

Rabbits were randomly allotted into three experimental groups ( 48 rabbits per treatment) and were housed in cages ( 2 rabbits/cage). The cages were equipped with a hopper for feed and an automatic nipple drinking system. The lighting cycle throughout the trial was $16 \mathrm{~h}$ of light and $8 \mathrm{~h}$ of dark. The building temperature was maintained within $18 \pm 4{ }^{\circ} \mathrm{C}$, with a relative humidity of $70 \pm 5 \%$.

The animals were fed ad libitum and had free access to water. Table 1 reports the ingredients and chemical composition of the experimental diets.

Table 1. Ingredients $(\mathrm{g} / \mathrm{kg}$ ) and chemical composition of experimental diets.

\begin{tabular}{cccc}
\hline Ingredients & C & Diet $^{\text {a }}$ SP1 & SP2 \\
\hline Maize & 282 & 279 & 276 \\
Alfalfa hay & 305 & 305 & 305 \\
Sunflower meal & 135 & 135 & 135 \\
Carob bean meal & 90 & 90 & 90 \\
Wheat & 80 & 80 & 80 \\
Oat & 53 & 53 & 53 \\
Cane molasses & 20 & 20 & 20 \\
Palm seed oil & 8 & 8 & 8 \\
Soybean oil & 7 & 7 & 7 \\
Calcium carbonate & 7 & 7 & 7 \\
Sodium Chloride & 3 & 3 & 3 \\
DL-Methionine (99\%) & 2.5 & 2.5 & 2.5 \\
Vitamin and mineral premix ${ }^{b}$ & 2.5 & 2.5 & 2.5 \\
Dicalcium phosphate & 2 & 2 & 2 \\
L-Lysine HCl (78.5\%) & 1.6 & 1.6 & 1.6 \\
Choline (75\%) & 1.4 & 1.4 & 1.4 \\
Dietary supplement & 0 & 3 & 6 \\
Chemical composition c & & & \\
Crude protein & 184 & 183.6 & 183.5 \\
Ether extract & 37.5 & 35.5 & 35.5 \\
Crude fiber & 187 & 186.8 & 187 \\
Ash & 86 & 85.7 & 85.8 \\
Nitrogen free extract & 507 & 507.1 & 506.9 \\
NDF & 302.1 & 301.5 & 301.7 \\
ADF & 195.8 & 195.4 & 195.3 \\
ADL & 39.9 & 39.5 & 39.5 \\
\hline
\end{tabular}

a $\mathrm{C}=$ control diet; SP1 = diet supplemented with $0.3 \%$ of brown seaweed and plant
polyphenols; SP2 = diet supplemented with $0.6 \%$ of brown seaweed and plant
polyphenols. b Supplied per $\mathrm{kg}$ diet: $13,500 \mathrm{I} . \mathrm{U}$. vitamin A (trans-retinyl acetate);
800 I.U. vitamin D3 (cholecalciferol); $35 \mathrm{mg}$ vitamin $\mathrm{E}(\alpha$-tocopherol min $91 \%), 35 \mathrm{mg}$
copper (cupric sulphate pentahydrate). ${ }^{c}$ Determined in triplicate.

The chemical composition was analyzed according to the methods of the Association of Analytical Chemists [17], following the recommendations of the European group on rabbit nutrition [18].

Table 2 reports the chemical composition, phenolic composition and carotenoid content of the feed supplement. The supplement phenolic compounds were determined using HPLC-UV-DAD [19]. The beta-carotene content of the feed supplement was performed according to Rakusa et al. [20]. 
Table 2. Chemical composition and polyphenols content of the dietary supplement.

\begin{tabular}{cc}
\hline Item & $\% \mathrm{DM}$ \\
\hline & $93.6 \pm 5.05$ \\
Dry matter & $7.2 \pm 0.99$ \\
Crude protein & $0.32 \pm 0.01$ \\
Ether extract & $11.2 \pm 1.02$ \\
Crude fiber & $49.6 \pm 3.18$ \\
Carbohydrates & $32.7 \pm 1.38$ \\
Ash & $\mathrm{mg} / \mathrm{kg} \mathrm{DM}$ \\
Chemical compounds: a & $402 \pm 30.89$ \\
B-Carotene & $1059.8 \pm 62.82$ \\
Phenolic acid: & \\
Syringic acid & $126.5 \pm 8.67$ \\
Hydroxycinnamic acids: & $105.5 \pm 8.09$ \\
Neochlorogenic acid & $21.4 \pm 3.65$ \\
Rosmarinic acid & \\
Trans sinapic acid & $2440.9 \pm 148.29$ \\
Chlorogenic acid & $272.4 \pm 20.82$ \\
Tannins: & \\
Ellagic acid & $53.9 \pm 5.68$ \\
Rutin & Flavonoids: \\
Myricetin &
\end{tabular}

\subsection{Sampling}

The animals were weighed at 0 and 42 days of the experimental trial and were monitored daily to assess the health conditions. Daily feed intake was recorded (feed offered and refused weekly). The data were used to calculate the average daily gain (ADG), average daily feed intake (ADFI) and feed conversion ratio (FCR).

At the end of the trial the rabbits (77 days old) were weighted and after a fasting period of $6 \mathrm{~h} 1$ male rabbit per cage (12 animals/group) were randomly selected and slaughtered. Rabbits were subjected to electrical stunning $(100 \mathrm{~V}, 50 \mathrm{~Hz}, 2-3 \mathrm{~s})$ and sacrificed by bleeding according to the guidelines established by the European Community (1099/2009/EC) for the protection of animals during slaughter [21].

Carcasses were chilled for $24 \mathrm{~h}$ at $+4{ }^{\circ} \mathrm{C}$ and then dissected, according to the recommendations of the WRSA [22], by removing the skin, distal part of the limbs, genital organs, bladder and the gastrointestinal tract. Carcasses were then weighted, and the dressing percentages were determined. Samples of whole Longissimus lumborum (LL) from the 7th thoracic vertebra to the 7th lumbar vertebra and whole thighs were collected. The physical parameters were evaluated on freshly cut LL muscle and Semimembranosus (SM) muscle. The whole muscles were then sampled for chemical and sensory analysis, vacuum packed and stored at $-20^{\circ} \mathrm{C}$. The chemical parameters were performed on LL and SM muscles and the sensory evaluation was assessed on the LL muscle and whole thighs.

\subsection{Physical and Chemical Parameters}

All the analyses were performed on LL muscle and Semimembranosus (SM) muscle. The pH and color parameters were measured $24 \mathrm{~h}$ after slaughter. The $\mathrm{pH}$ measurement was performed using a pH meter (HI98191 microcomputer; Hanna Instruments, Vila do Conde, Portugal), calibrated with a standard buffer of $\mathrm{pH} 4.0$ and 7.0.

Meat color parameters were evaluated at $24 \mathrm{~h}$ after slaughter on the fresh cut surface of LL and SM muscles, after 20 min of blooming, using a chromameter (Chromameter CR 300 Minolta Ltd., Osaka, Japan) equipped with a D65 light source and a $0^{\circ}$ viewing angle geometry according to the 
reflectance coordinates $\left(\mathrm{L}^{*}, \mathrm{a}^{*}, \mathrm{~b}^{*}\right)$. The instrument was calibrated using a white calibration plate (Calibration Plate CR-A43; Minolta Camera Co.). The color determination was assessed in triplicate.

The chemical composition of both muscles was determined according to the AOAC methods [17].

The cholesterol content was determined following the method of Du and Ahn [23], using a gas chromatographic method. The cholesterol was identified based on the retention time of the standard (Sigma Aldrich, St. Louis, CA, USA) and quantified with the Chrom Card Data System (version 1.17) software. All samples were analyzed in triplicate.

\subsection{Vitamin Content}

The $\alpha$-tocopherol and retinol content in LL and SM muscle were determined using the modified procedure of Zaspel and Csallany [24]. The samples were analyzed using an HPLC system (Kontron Instruments, Milan, Italy) with an autosampler (HPLC autosampler 360, Kontron Instruments, Milan, Italy) with a loop of $20 \mu \mathrm{L}$, a high-pressure pump and a C18 column $5 \mu \mathrm{m}, 150 \times 4.6 \mathrm{~mm}$ (Phenomenex, Torrance, CA, USA). The mobile phase was acetonitrile and methanol (75:25 $v / v)$ and the flow rate was $1 \mathrm{~mL}$ per min. The $\alpha$-tocopherol and retinol were identified using a fluorimeter detector, comparing the retention time with the standards (Sigma Aldrich, St. Louis, CA, USA). The quantification was performed using the Geminyx system (version 1.91).

\subsection{Sensory Analysis}

The sample preparation was performed after thawing thighs and LL muscle for $24 \mathrm{~h}$ at $4{ }^{\circ} \mathrm{C}$. The whole samples of LL and thighs were prepared in an uncovered stainless-steel dish in a conventional oven (REX, Milano, Italy) at $180^{\circ} \mathrm{C}$. A thermocouple (Pentronic AB, Gunnebobruk, Sweden) was used to register the sample core temperature and samples were removed at $79-80^{\circ} \mathrm{C}$. The roasted samples were then cut into $1.5 \mathrm{~cm}$ thick slices (Electrolux 50, 220-24, $\mathrm{kW0.2}$ ) and the slices were warmed to $60^{\circ} \mathrm{C}$ before the evaluation. A trained sensory panel, involving eight members familiar with descriptive analysis procedures [25], was employed. All evaluations were performed in a sensory laboratory equipped according to EN ISO 8598 recommendations [26]. The descriptors, definitions, and standards are reported in Palazzo et al. [27].

The sensory profile was assessed according to EN ISO 13,299 [25] and the panel evaluated the two samples (thigh and LL) on different days in triplicate. Within each session the design was balanced for order and carry-over effects [28]. During training and sampling, the panelists had access to unlimited water and unsalted crackers. They were requested to evaluate the intensity of each attribute by assigning a score between 1 (absence of the sensation) and 9 (extremely intense).

\subsection{Statistical Analysis}

Data were analyzed using SPSS software (SPSS, PC Statistics 25.0 SPSS Inc., IBM, Segrate, MI, Italy). Productive performance and slaughter and meat quality parameters were analyzed using one-way analysis of variance (ANOVA), with diet as the fixed effect. The sensory data were submitted to ANOVA with samples, judges, replicates, and their interactions as effects (EN ISO 13299, 2010). The significance of these effects was tested with F tests. Post-hoc pairwise contrasts were evaluated by Duncan's test. The cage was considered as the experimental unit for growth performance and the rabbit for the meat quality parameters. Data are reported as mean \pm SEM. Differences among treatments were considered significant at $p<0.05$.

\section{Results}

\subsection{Productive Parameters and Carcass Characteristics}

The growth performances and carcass parameters of rabbit fed experimental diets are reported in Table 3. The final weight of the rabbits did not differ among experimental groups $(p>0.05)$, even if the ADG tended to be higher $(p=0.09)$ in both the SP1 and SP2 groups. The ADFI result was lower 
$(p<0.05)$ in the SP1 group than the results in the other groups. The feed conversion ratio was positively affected $(p<0.001)$ by both the dosage of brown seaweed and plant polyphenols (SP1 and SP2).

Table 3. Growth performances of rabbits fed the control diet (C) and diet supplemented with $3 \mathrm{~g} / \mathrm{kg}$ (SP1) and $6 \mathrm{~g} / \mathrm{kg}$ (SP2) of brown seaweed and plant polyphenols.

\begin{tabular}{ccccc}
\hline Item & C & Diet SP1 & SP2 & $p$-Value \\
\hline Initial weight, g & $829.1 \pm 0.21$ & $838.7 \pm 0.22$ & $818.8 \pm 0.17$ & 0.686 \\
Final weight, g & $2657.2 \pm 58.62$ & $2757.9 \pm 41.54$ & $2864.1 \pm 35.51$ & 0.220 \\
ADG, g/d & $42.5 \pm 1.16$ & $45.7 \pm 1.04$ & $46.3 \pm 0.73$ & 0.090 \\
ADFI, g/d & $172.1 \pm 2.45^{\mathrm{a}}$ & $148.8 \pm 3.17^{\mathrm{b}}$ & $161.9 \pm 1.66^{\mathrm{a}}$ & 0.014 \\
FC & $3.95 \pm 0.04^{\mathrm{A}}$ & $3.25 \pm 0.06^{\mathrm{B}}$ & $3.49 \pm 0.03^{\mathrm{B}}$ & 0.001
\end{tabular}

ADG, average daily gain; ADFI, average daily feed intake; FC, feed conversion ratio. Data are reported as means \pm standard error of the means $(\mathrm{SEM}) ; \mathrm{n}=48^{\mathrm{a}, \mathrm{b}}$ values in the same row are different at $p<0.05 .{ }^{\mathrm{A}, \mathrm{B}}$ values in the same row are different at $p<0.01$.

The slaughter weight $(2791.3 \pm 69.2$ g C vs. $3001.2 \pm 59.4$ g SP1 vs. $2986.1 \pm 42.4$ g SP2; $p=0.021)$ and the carcass weight $(1473.4 \pm 38.6 \mathrm{~g}$ C vs. $1585.2 \pm 33.4 \mathrm{~g}$ SP1 vs. $1610.4 \pm 19.7 \mathrm{~g}$ SP2; $p=0.010)$ of the sampled rabbit $(n=12)$ resulted higher in groups fed brown seaweed and polyphenols (SP1 and SP2) than in the control. The dressing percentage resulted higher in SP2 group than the others $(52.8 \pm 0.37 \% \mathrm{C}$ vs. $52.4 \pm 0.32 \% \mathrm{SP} 1$ vs. $53.9 \pm 0.41 \% \mathrm{SP} 2 ; p=0.025)$.

\subsection{Meat Physical and Chemical Parameters}

The chemical composition of LL and SM muscle are reported in Tables 4 and 5, respectively. The physical parameters in both muscles were not affected $(p>0.05)$ by long term supplementation of both lactating does and the offspring with low and high dosage of seaweed and polyphenols. The nutritional parameters moisture, crude protein, ether extract and ash were also unaffected by dietary treatments $(p>0.05)$. The cholesterol content in LL muscle tended to be lower $(p=0.059)$ in SP2 than SP1 and the control groups. The cholesterol content of the SM muscle resulted lower $(p<0.01)$ in the group that received the high dosage of seaweed and polyphenols (SP2) than SP1 and the control groups. The cholesterol content reduction was about $-40.3 \%$ than control and $-36.4 \%$ than SP1 groups.

Table 4. Physical and chemical parameters of Longissimus lumborum muscle of rabbits fed the control diet (C) and diet supplemented with $3 \mathrm{~g} / \mathrm{kg}$ (SP1) and $6 \mathrm{~g} / \mathrm{kg}$ (SP2) of brown seaweed and plant polyphenols.

\begin{tabular}{ccccc}
\hline Item & C & Diet SP1 & SP2 & $p$-Value \\
\hline pH 24 h & $5.85 \pm 0.25$ & $5.91 \pm 0.21$ & $5.88 \pm 0.16$ & 0.222 \\
Color parameters & & & & \\
$\mathrm{L}^{*}$ & $55.85 \pm 0.39$ & $56.30 \pm 1.01$ & $56.44 \pm 0.81$ & 0.873 \\
$\mathrm{a}^{*}$ & $3.89 \pm 0.71$ & $3.99 \pm 0.32$ & $4.28 \pm 0.42$ & 0.911 \\
$\mathrm{~b}^{*}$ & $11.92 \pm 0.67$ & $11.00 \pm 0.52$ & $11.28 \pm 0.26$ & 0.484 \\
& & & \\
Chemical composition: & & & & \\
Moisture, \% & $73.23 \pm 0.18$ & $73.02 \pm 0.21$ & $72.84 \pm 0.18$ & 0.383 \\
Crude Protein, \% & $24.33 \pm 0.14$ & $24.52 \pm 0.17$ & $24.65 \pm 0.21$ & 0.404 \\
Ether extract, \% & $1.17 \pm 0.06$ & $1.05 \pm 0.06$ & $1.19 \pm 0.10$ & 0.547 \\
Ash, \% & $1.22 \pm 0.01$ & $1.36 \pm 0.08$ & $1.39 \pm 0.06$ & 0.132 \\
Cholesterol, $\mathrm{mg} / 100 \mathrm{~g}$ & $33.23 \pm 2.98$ & $28.18 \pm 1.24$ & $25.07 \pm 1.18$ & 0.059 \\
\hline
\end{tabular}

Data are reported as means \pm standard error of the means $(\mathrm{SEM}) ; \mathrm{n}=12$. 
Table 5. Physical and chemical parameters of Semimembranosus muscle of rabbits fed the control diet (C) and diet supplemented with $3 \mathrm{~g} / \mathrm{kg}$ (SP1) and $6 \mathrm{~g} / \mathrm{kg}$ (SP2) of brown seaweed and plant polyphenols.

\begin{tabular}{ccccc}
\hline Item & C & Diet SP1 & SP2 & $p$-Value \\
\hline pH $24 \mathrm{~h}$ & $5.77 \pm 0.20$ & $5.79 \pm 0.18$ & $5.82 \pm 0.21$ & 0.853 \\
Color parameters & & & & \\
$\mathrm{L}^{*}$ & $63.92 \pm 1.59$ & $63.84 \pm 2.01$ & $64.41 \pm 1.94$ & 0.951 \\
$\mathrm{a}^{*}$ & $6.01 \pm 0.64$ & $5.94 \pm 0.56$ & $6.11 \pm 0.74$ & 0.894 \\
$\mathrm{~b}^{*}$ & $3.92 \pm 0.32$ & $4.02 \pm 0.49$ & $3.78 \pm 0.56$ & 0.831 \\
& & & & \\
Chemical composition: & $74.29 \pm 0.86$ & $74.22 \pm 0.78$ & $74.17 \pm 0.72$ & 0.594 \\
Moisture, \% & $23.12 \pm 0.53$ & $23.37 \pm 0.73$ & $23.61 \pm 0.62$ & 0.338 \\
Crude Protein, \% & $1.66 \pm 0.46$ & $1.92 \pm 0.38$ & $1.51 \pm 0.43$ & 0.958 \\
Ether extract, \% & $1.21 \pm 0.06$ & $1.19 \pm 0.09$ & $1.15 \pm 0.07$ & 0.329 \\
Ash, \% & $39.85 \pm 4.48^{\mathrm{A}}$ & $37.39 \pm 2.07^{\mathrm{A}}$ & $23.78 \pm 1.17^{\mathrm{B}}$ & 0.002 \\
Cholesterol, $\mathrm{mg} / 100 \mathrm{~g}$ &
\end{tabular}

Data are reported as means \pm standard error of the means $(\mathrm{SEM}) ; \mathrm{n}=12$. ${ }^{\mathrm{A}, \mathrm{B}}$ values in the same row are different at $p<0.01$.

\subsection{Muscle Vitamin Content}

Figure 1 shows the $\alpha$-tocopherol (A) and retinol (B) content of both muscles in relation to dietary treatments. The $\alpha$-tocopherol content resulted higher $(p<0.001)$ in the LL and SM muscles of rabbit fed both dosages of brown seaweed and polyphenols (SP1 and SP2) than in the control. The retinol content was higher $(p<0.001)$ in both muscles of rabbit fed brown seaweed and plant polyphenols (SP1 and SP2) than in the control group.

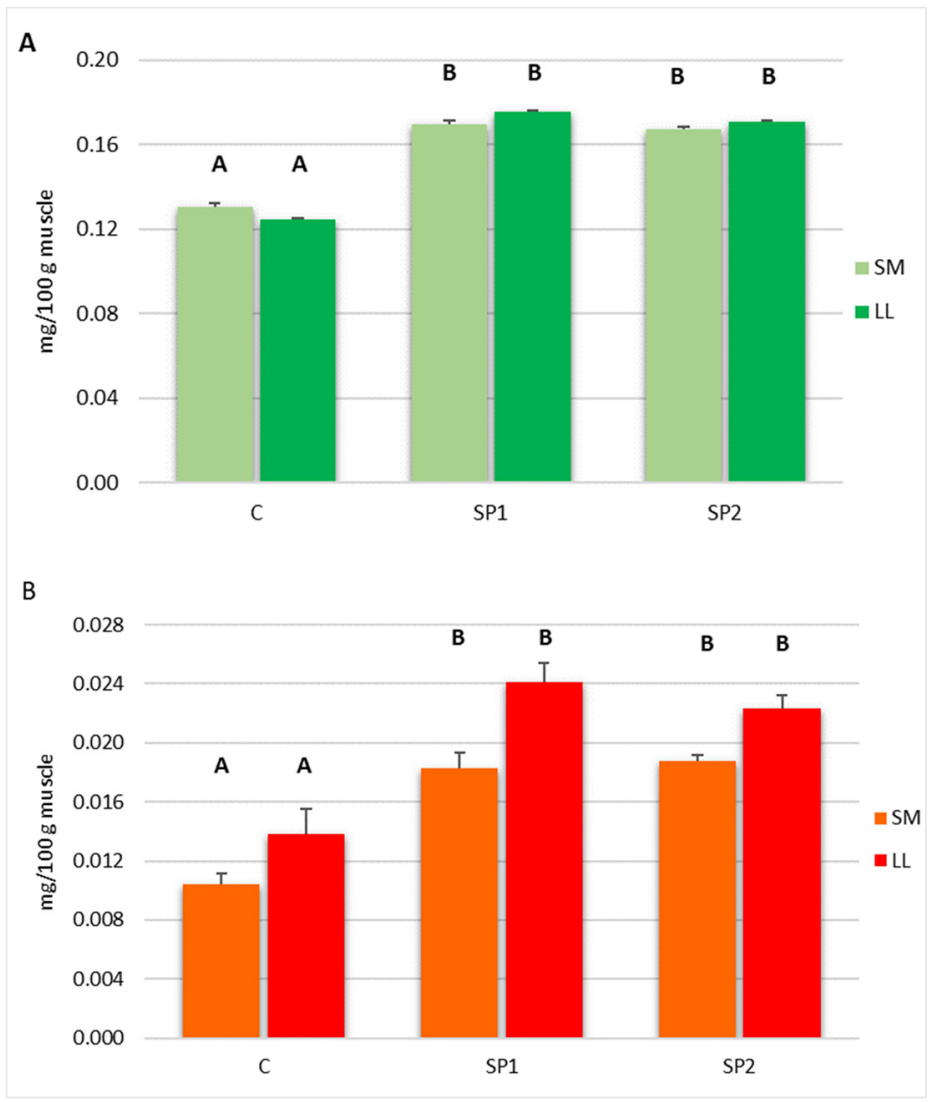

Figure 1. $\alpha$-tocopherol (A) and retinol (B) content of Longissimus lumborum (LL) and Semimembranosus muscle (SM) of rabbits fed control diet (C) and diet supplemented with $3 \mathrm{~g} / \mathrm{kg}$ (SP1) and $6 \mathrm{~g} / \mathrm{kg}$ (SP2) of brown seaweed and plant polyphenols. Data are reported as means \pm standard error of the means $(\mathrm{SEM}) ; \mathrm{n}=12$. ${ }^{\mathrm{A}, \mathrm{B}}$ values with different superscript letters are different at $p<0.001$. 


\subsection{Sensory Profile}

The $\mathrm{F}$ values for the measured parameters of the LL muscle and thigh sensory profile are reported in Tables 6 and 7, respectively. The data show that dietary supplementation with brown seaweed and plant polyphenols mixture affected $(p<0.05)$ the flavor and texture of the LL muscle. The $\mathrm{F}$ values for replicates and interactions were not affected $(p>0.05)$ for all the descriptors. In thigh, taste, flavor and texture were affected $(p<0.05)$ by dietary treatments. Judges presented differences $(p<0.05)$ for aroma, taste, flavor and texture as observed for LL muscle. The judges and the interaction of the treatments per judge revealed differences $(p<0.05)$ for aroma, taste, flavor and texture.

Table 6. The F value and statistical significance of treatments (C, SP1, SP2) and their interaction for sensory descriptors of Longissumus lumborum muscle, where the number of judges, $\mathrm{n}=8$, and the number of replicates, $\mathrm{n}=3$.

\begin{tabular}{|c|c|c|c|c|c|c|}
\hline Descriptors & Treatments & Judges & $\begin{array}{c}\text { F Value } \\
\text { Replicates }\end{array}$ & $\mathbf{T}^{*} \mathrm{~J}$ & $\mathbf{T}^{*} \mathbf{R}$ & $\mathbf{J}^{*} \mathbf{R}$ \\
\hline \multicolumn{7}{|l|}{ Aroma } \\
\hline Rabbit & 2.27 & 4.52 & 0.26 & 1.68 & 1.55 & 0.85 \\
\hline Liver & 0.05 & 1.73 & 1.37 & 0.70 & 1.75 & 1.03 \\
\hline Metallic & 2.27 & $4.83^{* *}$ & 0.08 & 1.63 & 1.41 & 0.83 \\
\hline \multicolumn{7}{|l|}{ Taste } \\
\hline Sweet & 0.71 & $2.67 *$ & 1.33 & 1.64 & 0.46 & 1.23 \\
\hline Salty & 2.12 & $2.83 *$ & 0.63 & 1.10 & 1.16 & 1.22 \\
\hline \multicolumn{7}{|l|}{ Flavor } \\
\hline Rabbit & $4.61 *$ & 1.37 & 0.73 & 0.95 & 2.25 & 1.45 \\
\hline Liver & $12.88^{* * *}$ & $5.56^{* * *}$ & 0.30 & $3.41^{* *}$ & 0.77 & 1.47 \\
\hline Metallic & $5.18 *$ & $5.83^{* * *}$ & 0.45 & $2.19 *$ & 0.30 & 1.00 \\
\hline \multicolumn{7}{|l|}{ Texture } \\
\hline Tender & $8.53^{* *}$ & $7.80^{* * *}$ & 0.81 & $2.98^{* *}$ & 0.48 & 1.12 \\
\hline Juicy & $20.31^{* * *}$ & $2.69 *$ & 2.04 & $3.84^{* *}$ & 1.00 & 1.12 \\
\hline Stringy & $3.56 *$ & $3.26 *$ & 1.04 & $4.83^{* * *}$ & 1.48 & 0.77 \\
\hline
\end{tabular}

Table 7. The F value and statistical significance of treatments (C, SP1, SP2) and their interaction for sensory descriptors of thigh, where the number of judges, $n=8$, and the number of replicates, $n=3$.

\begin{tabular}{|c|c|c|c|c|c|c|}
\hline Descriptors & Treatments & Judges & $\begin{array}{c}\text { F Value } \\
\text { Replicates }\end{array}$ & $\mathbf{T}^{*} \mathrm{~J}$ & $\mathbf{T}^{*} \mathbf{R}$ & $\mathbf{J}^{*} \mathbf{R}$ \\
\hline \multicolumn{7}{|l|}{ Aroma } \\
\hline Rabbit & 1.91 & $2.58 *$ & 0.09 & 1.02 & 1.28 & 0.80 \\
\hline Liver & 0.11 & 1.35 & 1.15 & 0.65 & 1.07 & 1.09 \\
\hline Metallic & 035 & $5.68 * *$ & 0.89 & $2.07 *$ & 0.56 & 1.10 \\
\hline \multicolumn{7}{|l|}{ Taste } \\
\hline Sweet & $3.97 *$ & 0.70 & 2.90 & 1.29 & 2.42 & 0.81 \\
\hline Salty & 0.36 & $4.06^{* *}$ & 1.02 & $2.18 *$ & 0.37 & 0.71 \\
\hline \multicolumn{7}{|l|}{ Flavor } \\
\hline Rabbit & $6.51 * *$ & $3.26 *$ & 1.22 & 1.26 & 0.58 & 2.42 \\
\hline Liver & 2.66 & $2.46 *$ & 1.66 & 1.47 & 1.42 & 1.43 \\
\hline Metallic & $2.97 *$ & $5.09^{* * *}$ & 0.95 & 1.84 & 1.13 & 1.17 \\
\hline \multicolumn{7}{|l|}{ Texture } \\
\hline Tender & $16.95^{* * *}$ & $4.44^{* *}$ & 0.93 & $5.23^{* * *}$ & 0.97 & 0.46 \\
\hline Juicy & $12.92^{* * *}$ & 1.47 & 0.57 & $4.92^{* * *}$ & 0.86 & 0.71 \\
\hline Stringy & $7.45^{* *}$ & $14.44^{* * *}$ & 0.39 & $9.57^{* * *}$ & 0.39 & 0.84 \\
\hline
\end{tabular}


Figure 2 reports the least squares mean of the different attributes for the LL muscle (A) and thighs (B). In LL muscle the rabbit, liver and metallic flavors were affected by the high dosage of brown seaweed and plant polyphenols, resulting higher $(p<0.05)$ in the SP2 group than the SP1 group and the control groups. The texture parameters were also enhanced in muscle from rabbit fed the natural mixture. In particular, tenderness and juiciness resulted higher $(p<0.05)$ in both groups receiving brown seaweed and plant polyphenols (SP1 and SP2) than the controls. The stringiness resulted lower $(p<0.05)$ in the control and SP2 groups than results in the SP1 group. The attributes related to aroma and taste were unaffected $(p>0.05)$ by dietary treatments. In tights the rabbit and metallic flavors were affected by brown seaweed and plant polyphenols, resulting higher $(p<0.05)$ in both groups receiving the supplement (SP1 and SP2) than in the controls. The sweety taste was positively affected $(p<0.05)$ by the high dosage of natural supplement, in fact, thigh from SP2 group resulted sweetness higher than controls. Tenderness and juiciness resulted higher $(p<0.05)$ in groups receiving the high dosage of brown seaweed and plant polyphenols (SP2) than the SP1 group and the controls. The stringiness resulted lower $(p<0.05)$ in the control group than the SP1 group. The attributes related to aroma were unaffected $(p>0.05)$ by dietary treatments.

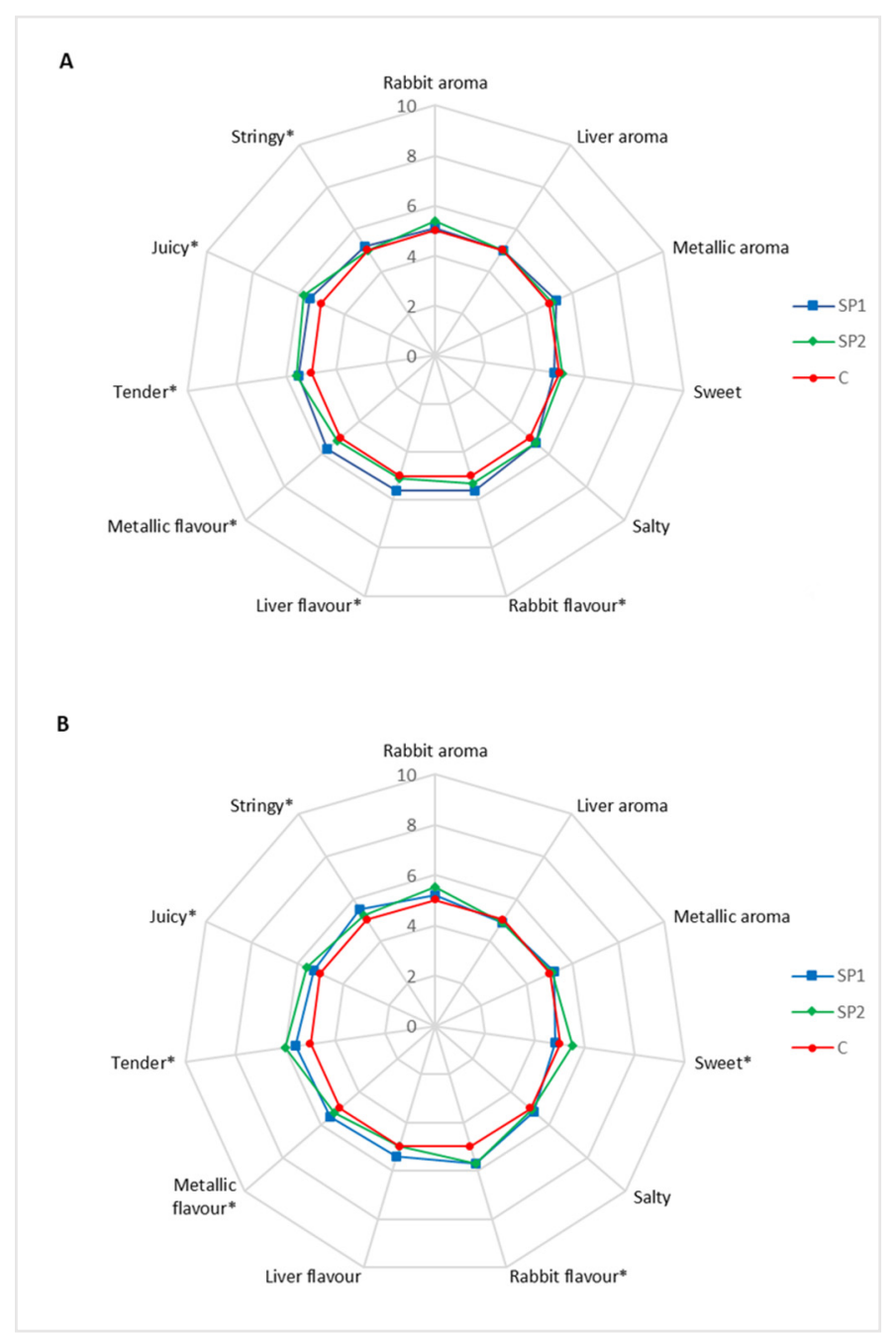

Figure 2. Spider plot of the sensory profile of Longissimus lumborum muscle (A) and thigh (B) of rabbit fed the control diet (C) and the diet supplemented with $3 \mathrm{~g} / \mathrm{kg}$ (SP1) and $6 \mathrm{~g} / \mathrm{kg}$ (SP2) of brown seaweed and plant polyphenols. ${ }^{*}$ Significant at $p<0.05$. 


\section{Discussion}

In the recent years, several studies reported the effect of dietary supplementation with plant polyphenols in rabbit to improve growth performances and meat quality parameters [9,29]. However, there are only few studies on dietary supplementation with seaweed in rabbit. Previous study reported that dietary green seaweed Ulva Lactuca in does and male rabbit improve reproductive parameters [30,31]. Moreover, Dalle Zotte et al. [32] reported that a mixture containing dietary microalga Spirulina and Thymus vulgaris, did not affect growth performance and energy or nutrients digestibility.

To the best of our knowledge, the first study describing the effect of dietary brown seaweed and plant polyphenols in rabbit is our recent study limited to the growing phase [14], but the effects of long term supplementation of this mixture from lactating does to rabbit slaughter has been not yet studied. The present data showed that ADG tended to be higher in rabbit fed the natural mixture and the feed conversion ratio was enhanced in rabbit fed the dietary supplement, suggesting a better feed conversion due to the probiotic, antibacterial and antioxidant effects of the natural mixture used [11]. An enhancement of nutrient digestibility was also observed in several animal species fed seaweed [12]. The present data are in line with studies in rabbit showing that natural extract dietary supplementation positively affected rabbit's growth performances $[6,10]$.

The data on carcass characteristics showed an enhancement in rabbit fed the natural dietary supplement. Previous studies reported no effects of dietary supplementation with polyphenols on carcass characteristics in pigs and rabbit $[9,33]$. Other studies in pigs reported an enhancement of carcass characteristics due to polyphenols supplementation [34,35]. These different results are probably due to the length and dosage of dietary supplementation and the active principles content of the plant extract used.

The present data show that dietary supplementation with polyphenols and brown seaweed did not affect $\mathrm{pH}$ and color parameters in both muscles, in agreement with our previous study in rabbit fed the same mixture [14]. The data fall in the means of the values reported in other studies for LL and SM muscles $[36,37]$.

Likewise, the chemical composition of the LL and SM muscles was not affected by the dietary treatments, except for the cholesterol content. Comparing with our study in rabbit fed the same mixture [14], the dietary supplementation of both the does and the offspring reduces the cholesterol content in both muscles, and this reduction compared to controls was relevant in the SP2 groups $(-24.5 \%$ and $-40.3 \%$ in LD and SM muscle, respectively).

Previous studies reported a lowering cholesterol effect of seaweed in livestock and humans. Al-Harthi and El-Deek [38] reported that dietary supplementation with 3-6\% of brown seaweed in laying hens improved egg quality, and decreased yolk cholesterol content. In humans, seaweed intake was positively linked to a modulation of blood glucose and cholesterol [39]. This mechanism is probably linked to the activity of the seaweed polysaccharide fucoidan that decreases cholesterol absorption and increases its excretion, modulating reverse cholesterol transport-related protein expression [40]. A cholesterol lowering effect was also observed in rabbit and hares fed plant extract containing polyphenols [41,42].

Our results show that the dietary mixture of brown seaweed and plant polyphenols enhances the content of $\alpha$ tocopherol and retinol in both LL and SM muscles. Seaweeds show antioxidant properties due to the phenols, carotenoid fucoxanthin, tannins, phlorotannins and polysaccharides content. Furthermore, seaweeds are an excellent source of vitamins and, above all, brown seaweeds contain a large amount of $\alpha$ tocopherol and carotenoid [11]. In fact, previous studies in pork reported that seaweed dietary supplementation enhances oxidative stability of LD muscle due to higher muscle $\alpha$ tocopherol content $[43,44]$.

Moreover, plant extract containing polyphenols increased $\alpha$ tocopherol and retinol levels in several tissues, reducing the oxidative markers [45]. In fact, an earlier study in pork, rabbit and hares reported that natural extract containing polyphenols enhanced muscle $\alpha$ tocopherol and retinol [27,46,47]. 
The data on sensory profile revealed that the dietary mixture of brown seaweed and plant polyphenols affected the flavor in both LL muscle and thigh, even if the differences are hardly perceived. The texture attributes related to tenderness, juiciness and stringiness was improved in in both LL muscle and thigh from rabbit fed the natural mixture. The judges and the interaction of the treatments per judges revealed differences for aroma, taste, flavor and texture, but this is common in sensory evaluations, due to the different use of the scale [48]. Even if there is selection and training of judges, some variability always remains, but the interaction treatments per judges was not significant for most descriptors, indicating low variability among the panel members.

In literature no previous study reported the effects of dietary brown seaweed supplementation on meat sensory quality parameters while several studies reported the effects of dietary plant polyphenols on this parameter. Dietary plant polyphenols from Lippia spp. improve the texture parameters related to tenderness and juiciness in donkey and horse Longissimus dorsi muscle and it is probably related to the protection against the oxidation process [27]. Moreover, Zhao et al. [49] also reported an improvement of tenderness of lamb meat due to dietary supplementation with wine grape pomace, a rich source of polyphenols. Probably, the protection of the proteolytic enzymes $\mu$-calpain and m-calpain from the oxidative process, increases their functionality, enhancing meat tenderness $[50,51]$.

\section{Conclusions}

Our results show that dietary supplementation with a high dosage of brown seaweeds and plant polyphenols of both lactating does and the offspring have a positive effect on the average daily feed intake and feed conversion ratio, without affecting other meat physical parameters.

Nutritional characteristics of both LL and SM muscle were positively affected by the natural extract, with a reduction of the cholesterol content and an increase of $\alpha$ tocopherol and retinol content. Moreover, an improvement of the sensory quality perceived by consumers in terms of texture was observed in both LL muscle and thigh from rabbit fed the high dosage of the natural mixture.

From these data, we can conclude that the long term supplementation of both lactating does and the offspring with a high dosage of brown seaweeds and plant polyphenols is a valid approach to boost rabbits' performance and enhance meat nutritional and sensory parameters.

Author Contributions: Conceptualization, C.C. and D.C.; investigation, F.V., R.R., S.R. and M.P.; data curation, F.V. and R.R.; writing—original draft preparation, R.R.; writing-review and editing, C.C., F.V., R.R., S.R. and M.P.; project administration, supervision C.C. and D.C. All authors have read and agreed to the published version of the manuscript.

Funding: The study was conducted within research funds of the University of Milan (PSR2019_DIP_027_CCORI_01).

Acknowledgments: The authors would like to thank the technical staff of the National Agricultural and Food Centre, Nitra (Slovak Republic) for the availability of rabbit, and technical support during the whole experimental period.

Conflicts of Interest: The authors declare no conflict of interest.

\section{References}

1. EFSA Panel on Animal Health and Welfare (AHAW). Health and welfare of rabbit farmed in different production system. EFSA J. 2020, 18, e05944.

2. Petracci, M.; Cavani, C. Rabbit meat processing: Historical perspective to future directions. World Rabbit Sci. 2013, 21, 217-226. [CrossRef]

3. Szendrő, K.; Szabó-Szentgróti, E.; Szigeti, O. Consumers' Attitude to Consumption of Rabbit Meat in Eight Countries Depending on the Production Method and Its Purchase Form. Foods 2020, 9, 654. [CrossRef]

4. Gondret, F.; Larzul, C.; Combes, S.; De Rochambeau, H. Carcass composition, bone mechanical properties, and meat quality traits in relation to growth rate in rabbits. J. Anim. Sci. 2005, 83, 1526-1535. [CrossRef]

5. Hernandez, P.; Arino, B.; Grimal, A.; Blasco, A. Comparison of carcass and meat characteristics of three rabbit lines selected for litter size or growth rate. Meat Sci. 2006, 73, 645-650. [CrossRef] [PubMed]

6. Dalle Zotte, A.; Celia, C.; Szendrő, Z.S. Herbs and spices inclusion as feed stuff or additive in growing rabbit diets and as additive in rabbit meat: A review. Livest. Sci. 2016, 189, 82-90. [CrossRef] 
7. Petrescu, D.C.; Petrescu-Mag, R.M. Consumer behaviour related to rabbit meat as functional food. World Rabbit Sci. 2018, 26, 321-333. [CrossRef]

8. Román Luis, S.; Sánchez-Siles, M.; Siegrist, M. The importance of food naturalness for consumers: Results of a systematic review. Trends Food Sci. Technol. 2017, 67, 44-57. [CrossRef]

9. Palazzo, M.; Vizzarri, F.; Arvay, J.; D’Alessandro, A.G.; Martemucci, G.; Casamassima, D.; Ratti, S.; Corino, C.; Rossi, R. Dietary effect of dried bay leaves (Laurus nobilis) meal on selected productive performances and on quality meat traits in growing rabbits. Livest. Sci. 2020, 242, 104301. [CrossRef]

10. Miteva, D.; Velikov, K.; Ivanova, S.; Dimov, K. Production of rabbit meat with functional properties. Agro Life Sci. J. 2020, 9, 221-228.

11. Corino, C.; Modina, S.C.; Di Giancamillo, A.; Chiapparini, S.; Rossi, R. Seaweeds in Pig Nutrition. Animals 2019, 9, 1126. [CrossRef] [PubMed]

12. Morais, T.; Inácio, A.; Coutinho, T.; Ministro, M.; Cotas, J.; Pereira, L.; Bahcevandziev, K. Seaweed Potential in the Animal Feed: A Review. J. Mar. Sci. Eng. 2020, 8, 559. [CrossRef]

13. Vizzarri, F.; Chiapparini, S.; Corino, C.; Casamassima, D.; Palazzo, M.; Parkanyi, V.; Ondruska, L.; Rossi, R. Dietary supplementation with natural extracts mixture: Effects on reproductive performances, blood biochemical and antioxidant parameters in rabbit does. Ann. Anim. Sci. 2019. [CrossRef]

14. Rossi, R.; Vizzarri, F.; Chiapparini, S.; Ratti, S.; Casamassima, D.; Palazzo, M.; Corino, C. Effects of dietary levels of brown seaweeds and plant polyphenols on growth and meat quality parameters in growing rabbit. Meat Sci. 2020, 161, 107987. [CrossRef] [PubMed]

15. European Community. Council Directive 2010/63/EU of 22 September 2010 on the Protection of Animals Used for Scientific Purposes. 2010. Available online: Eurlex.europa.eu/LexUriServ/LexUriServ.do?uri=OJ:L: 2010:276:0033:0079:EN:PDF (accessed on 30 September 2020).

16. Tosi, G.; (Experimental Zooprophylactic Institute of the Lombardy and Emilia, Forlì, Italy). Personal communication, 2012.

17. AOAC. Official Methods of Analysis, 17th ed.; Association of Official Analytical Chemists: Arlington, VA, USA, 2002.

18. European Group on Rabbit Nutrition (EGRN). Technical note: Attempts to harmonize chemical analyses of feeds and faeces for rabbit feeding evaluation. World Rabbit Sci. 2001, 9, 57-64.

19. Russo, R.; Pucci, L.; Giorgetti, L.; Árvay, J.; Vizzarri, F.; Longo, V.; Pozzo, L. Polyphenolic characterisation of plant mixture (Lisosan ${ }^{\circledR}$ reduction) and its hypocholesterolaemic effect in high fat diet-fed mice. Nat. Prod. Res. 2017, 33, 651-658. [CrossRef] [PubMed]

20. Rakusa, Z.T.; Srecnik, E.; Roskar, R. Novel HPLC-UV method for simultaneous determination of fat-soluble vitamins and coenzyme Q10 in medicines and supplements. Acta Chim. Slov. 2017, 64, 523-529. [CrossRef] [PubMed]

21. Council of the European Union. Council Regulation (EC) No. 1099/2009 of 24 September 2009 on the Protection of Animals at the Time of Killing. 2009. Available online: Eur-lex.europa.eu/LexUriServ/ LexUriServ.do?uri=OJ:L:2009:303:0001:0030:EN:PDF (accessed on 30 September 2020).

22. Blasco, A.; Ouhayoun, J. Harmonization of criteria and terminology in rabbit meat research. Revised proposal. World Rabbit Sci. 1996, 4, 93-99. [CrossRef]

23. Du, M.; Ahn, D.U. Simultaneous analysis of tocopherols, cholesterol, and phytosterols using gas chromatography. J. Food Sci. 2002, 67, 1696-1700. [CrossRef]

24. Zaspel, B.J.; Csallany, A.S. Determination of alpha-tocopherol in tissues and plasma by high-performance liquid chromatography. Anal. Biochem. 1983,1, 146-150. [CrossRef]

25. International Organization for Standardization. Sensory Analysis-Methodology-General Guidance to Establish a Sensory Profile; ISO 13299; ISO: Geneva, Switzerland, 2010.

26. International Organization for Standardization. Sensory Analysis: General Guidance for Design of Test Rooms; ISO 8598; ISO: Geneva, Switzerland, 1989.

27. Palazzo, M.; Vizzarri, F.; Nardoia, M.; Ratti, S.; Pastorelli, G.; Casamassima, D. Dietary Lippia citriodora extract in rabbit feeding: Effects on quality of carcass and meat. Arch. Anim. Breed. 2015, 58, 355-364. [CrossRef]

28. MacFie, H.J.; Bratchell, N.; Greenhoff, K.; Vallis, L.V. Designs to balance the effect of order of presentation and first-order carry-over effect in halls tests. J. Sens. Stud. 1989, 4, 129-148. [CrossRef] 
29. Dabbou, S.; Gai, F.; Renna, M.; Rotolo, L.; Dabbou, S.; Kovitvadhi, C.L.A.; Brugiapaglia, A.; De Marco, M.; Helal, A.N.; Zoccarato, I.; et al. Inclusion of bilberry pomace in rabbit diets: Effects on carcass characteristics and meat quality. Meat Sci. 2017, 124, 77-83. [CrossRef] [PubMed]

30. El-banna, S.G.; Hassan, A.A.; Okab, A.B.; Koriem, A.A.; Ayoub, M.A. Effect of feeding diets supplemented with seaweed on growth performance and some blood hematological and biochemical characteristics of male Baladi rabbits. In Proceedings of the 4th International Conference on Rabbit Production in Hot Climates, Sharm Elsheikh, Egypt, 24-27 February 2005; pp. 373-382.

31. Okab, A.B.; Samara, E.M.; Abdoun, K.A.; Rafay, J.; Ondruska, L.; Parkanyi, V.; Pivko, J.; Ayoub, M.A.; Al-Haidary, A.A.; Riyadh, S.A.; et al. Effects of dietary seaweed (Ulva lactuca) supplementation on the reproductive performance of buck and doe rabbits. J. Appl. Anim. Res. 2013, 41, 347-355. [CrossRef]

32. Dalle Zotte, A.; Sartori, A.; Bohatir, P.; Remignon, H.; Ricci, R. Effect of dietary supplementation of Spirulina (Arthrospira platensis) and thyme (Thymus vulgaris) on growth performance, apparent digestibility and health status of companion dwarf rabbits. Livest. Sci. 2013, 152, 182-191. [CrossRef]

33. Korniewicz, D.; Rózanski, H.; Usydus, Z.; Dobrzanski, Z.; Korniewicz, A.; Kaczmarek, P.; Frankiewicz, A.; Szulc, K. Efficiency of plant extracts (herbiplant cs) in pigs fattening. Pol. J. Food Nutr. Sci. 2007, 57, 309-315.

34. Rossi, R.; Stella, S.; Ratti, S.; Maghin, F.; Tirloni, E.; Corino, C. Effects of antioxidant mixtures in the diet of finishing pigs on the oxidative status and shelf life of Longissimus dorsi muscle packaged under modified atmosphere. J. Anim. Sci. 2017, 95, 4986-4997. [CrossRef]

35. Dávila-Ramírez, J.L.; Munguía-Acosta, L.L.; Morales-Coronado, J.G.; García-Salinas, A.D.; González-Ríos, H.; Celaya-Michel, H.; Sosa-Castañeda, J.; Sánchez-Villalba, E.; Anaya-Islas, J.; Barrera-Silva, M.A. Addition of a mixture of plant extracts to diets for growing-finishing pigs on growth performance, blood metabolites, carcass traits, organ weight as a percentage of live weight, quality and sensorial analysis of meat. Animals 2020, 10, 1229. [CrossRef]

36. Kozioł, K.; Maj, D.; Bieniek, J. Change in the color and $\mathrm{pH}$ of rabbit meat in the aging process. Med. Weter. 2015, 71, 104-108.

37. Tůmová, E.; Bízková, Z.; Skřivanová, V.; Chodová, D.; Martinec, M.; Volek, Z. Comparisons of carcass and meat quality among rabbit breeds of different sizes, and hybrid rabbits. Livest. Sci. 2014, 165, 8-14. [CrossRef]

38. Al-Harthi, M.A.; El-Deek, A.A. Effect of different dietary concentrations of brown marine algae (Sargassum dentifebium) prepared by different ways on plasma and yolk lipid profiles, yolk total carotene and lutein plus zeaxanthin of laying hens. Ital. J. Anim. Sci. 2012, 11, e64. [CrossRef]

39. Brown, E.M.; Allsopp, P.J.; Magee, P.J.; Gill, C.I.; Nitecki, S.; Strain, C.R.; McSorley, E.M. Seaweed and human health. Nutr. Rev. 2014, 72, 205-216. [CrossRef] [PubMed]

40. Yang, Z.; Liu, G.; Wang, Y.; Yin, J.; Wang, J.; Xia, B.; Li, T.; Yang, X.; Hou, P.; Hu, S.; et al. Fucoidan A2 from the Brown Seaweed Ascophyllum nodosum Lowers Lipid by Improving Reverse Cholesterol Transport in C57BL/6J Mice Fed a High-Fat Diet. J. Agric. Food Chem. 2019, 67, 5782-5791. [CrossRef] [PubMed]

41. Vizzarri, F.; Nardoia, M.; Palazzo, M. Effect of dietary Lippia citriodora extract on productive performance and meat quality parameters in hares (Lepus europaeus Pall.). Arch. Tierzucht 2014, 57, 1-7. [CrossRef]

42. Vizzarri, F.; Palazzo, M.; D'Alessandro, A.G.; Casamassima, D. Productive performance and meat quality traits in growing rabbit following the dietary supplementation of Lippia citriodora, Raphanus sativus and Solanum lycopersicum extracts. Livest. Sci. 2017, 200, 53-59. [CrossRef]

43. Rajauria, G.; Draper, J.; McDonnel, M.; O'Doherty, J.V. Effect of dietary seaweed extracts, galacto oligosaccharide and vitamin E supplementation on meat quality parameters in finisher pigs. Innov. Food Sci. Emerg. Technol. 2016, 37, 269-275. [CrossRef]

44. Moroney, N.C.; O'Grady, M.N.; Robertson, R.C.; Stanton, C.; O’Doherty, J.V.; Kerry, J.P. Influence of level and duration of feeding polysaccharide (laminarin and fucoidan) extracts from brown seaweed (Laminaria digitata) on quality indices of fresh pork. Meat Sci. 2015, 99, 132-141. [CrossRef]

45. Corbi, G.; Conti, V.; Komici, K.; Manzo, V.; Filippelli, A.; Palazzo, M.; Vizzari, F.; Davinelli, S.; Di Costanzo, A.; Scapagnini, G.; et al. Phenolic Plant Extracts Induce Sirt1 Activity and Increase Antioxidant Levels in the Rabbit's Heart and Liver. Oxid. Med. Cell. Longev. 2018, 2018, 2731289. [CrossRef]

46. Rossi, R.; Pastorelli, G.; Cannata, S.; Tavaniello, S.; Maiorano, G.; Corino, C. Effect of long term dietary supplementation with plant extract on carcass characteristics meat quality and oxidative stability in pork. Meat Sci. 2013, 95, 542-548. [CrossRef] 
47. Palazzo, M.; Schiavitto, M.; Cinone, M.; Vizzarri, F. Rabbit metabolic response and selected meat quality traits. Evaluation of dietary PLX ${ }^{\circledR} 23$ and LycoBeads ${ }^{\circledR}$ feed supplement. J. Anim. Physiol. Anim. Nutr. 2019, 103, 383-394. [CrossRef]

48. Lea, P.; Rødbotten, M.; Næs, T. Analysis of Variance for Sensory Data; Chirchester John Wiley \& Sons Ltd.: New York, NY, USA, 1997.

49. Zhao, J.X.; Li, Q.; Zhang, R.X.; Liu, W.Z.; Ren, Y.S.; Zhang, C.X.; Zhang, J.X. Effect of dietary grape pomace on growth performance, meat quality and antioxidant activity in ram lambs. Anim. Feed Sci. Technol. 2018, 236, 76-85. [CrossRef]

50. Morán, L.; Andrés, S.; Bodas, R.; Prieto, N.; Giráldez, F.J. Meat texture and antioxidant status are improved when carnosic acid is included in the diet of fattening lambs. Meat Sci. 2012, 91, 430-434. [CrossRef] [PubMed]

51. Huff-Lonergan, E.; Lonergan, S.M. Mechanisms of water-holding capacity of meat: The role of postmortem biochemical and structural changes. Meat Sci. 2005, 71, 194-204. [CrossRef] [PubMed]

Publisher's Note: MDPI stays neutral with regard to jurisdictional claims in published maps and institutional affiliations.

(C) 2020 by the authors. Licensee MDPI, Basel, Switzerland. This article is an open access article distributed under the terms and conditions of the Creative Commons Attribution (CC BY) license (http://creativecommons.org/licenses/by/4.0/). 